REVISTA CHILENA DE LITERATURA

Noviembre 2020, Número 102, 139-162

\title{
BLEST GANA: EL CALEIDOSCOPIO INICIAL
}

\author{
Laura Janina Hosiasson \\ Universidade de São Paulo \\ São Paulo, Brasil \\ lhosiass@uol.com.br
}

\section{RESUMEN / ABSTRACT}

A estas alturas, cuando la envergadura de Alberto Blest Gana resulta incuestionable dentro del contexto de la narrativa hispanoamericana en el siglo XIX, no se justifica más el absoluto descaso que ha seguido sufriendo su primera producción, aquella que se inicia en 1853 y llega hasta 1859 , antes del premio de 1860 . El conjunto de estas novelas, así como la evidente y rica contradicción de todos los postulados del escritor, leídos a la luz del presente, parecen dirigir sus ramas hacia la percepción premonitoria de un esquema económico global perverso en las entrañas del aparato nacional político y social. Este ensayo se propone presentar algunas de las posibilidades de lectura de ese rico material.

Palabras Clave: Alberto Blest Gana, siglo XIX, narrativa chilena.

\section{BLEST GANA: THE INICIAL CALEIDOSCOPE}

At this point, when the breath of work of Alberto Blest Gana is unquestionably engrained within the context of XIX century hispanic-american narrative, we can no longer justify the dismissive approach that has been adopted with his earlier work, that which was composed from 1853 until 1859. The body of those novels, as it is true with the evident and fruitful contradiction that exists in all of the author's writings, when read from the perspective of present times, seems to direct its prongs towards a predictive assumption of an evil global economic scheme, that exists deep within the guts of the social and political national apparatus. This essay hopes to bring to light a few of the many possible ways of reading into this flush production.

KEYWORDS: Alberto Blest Gana, 19th century, Chilean narrative.

Recepción: 05/07/2020

Aprobación: 24/08/2020 
En 1853 aparecieron publicadas las primeras dos crónicas y la primera novela de Alberto Blest Gana, en el semanario El Museo dirigido por el amigo de toda la vida, su contemporáneo, Diego Barros Arana. El espacio concedido para esas colaboraciones ${ }^{1}$ puede impresionar si consideramos que se trataba de un principiante y que el semanario duró solamente 28 semanas, entre junio y diciembre de 1853. Barros Arana fue siempre un incentivador de Blest Gana y viceversa. El epistolario de ambos así lo confirma y no hay que olvidar que la familia de "los intelectuales patricios dominados por el modelo renacentista del letrado" (Ramos 9) era tan pequeña en el Chile del XIX, que casi rayaba en la promiscuidad. Si no estaban emparentados, eran amigos de la familia, se habían educado juntos en el Instituto Nacional y vivían a pocas cuadras de distancia, frecuentando las mismas tertulias, en el cuadrilátero "civilizado" y minúsculo de la capital ${ }^{2}$. Entre ellos figuraban sus hermanos, Guillermo y Joaquín, Diego Barros Arana, José Antonio Donoso, José Victorino Lastarria, Benjamín Vicuña Mackenna, Domingo Santa María, Federico Errázuriz, los hermanos Guillermo y Manuel Antonio Matta, Francisco y Manuel Bilbao y Juan Domingo y Justo Arteaga Alemparte, todos ellos jóvenes intelectuales liberales, con algunos de los cuales lo unirá una profunda amistad y a quienes dedicará algunas de sus novelas. Sin embargo, su forma de integrarse al movimiento se alejará rápidamente de la intrepidez y la osadía de quienes ocuparon las líneas de frente, arriesgando muchas veces sus vidas. Blest Gana prefirió desde temprano ocupar un puesto en la retaguardia desde donde poder observar.

Tres años más tarde, una carta de 1856 a otro gran amigo de juventud, José Antonio Donoso (Donoso 14), en la cual se hace cargo del análisis

En 1853, publicó en El Museo la novela Una escena social, en ocho entregas (del 3 de septiembre al 22 de octubre); las dos crónicas, "Las Manías" (el 19 de noviembre) y "Un baile en Santiago" (el 3 de diciembre); además de un poema, "Al corazón" (fecha no localizada).

Vale la pena reproducir aquí la descripción de ese grupo hecha por Domingo Amunátegui Solar, en 1920: "Los jóvenes de nuestro tiempo no pueden formarse una idea exacta de lo que era entonces la alta sociedad de Santiago. Timorata y orgullosa, estaba compuesta de un pequeño grupo de familias, en su mayor parte establecidas en las calles de Santo Domingo, las Monjitas, la Merced, Catedral, Compañía, Ahumada y Estado, alrededor de la Plaza, despreciativas de los que no tenían fortuna para vivir en el centro, y celosas de mantener la pureza de las doctrinas, ya que en el hecho a menudo distinguidos hogares ocultaban en el más impenetrable secreto faltas gravísimas contra la moralidad de las costumbres" (Amunátegui Solar 26). 
de un manuscrito, comprueba que Blest Gana era considerado por sus contemporáneos y se sentía un literato con experiencia suficiente como para aconsejar y evaluar la producción de sus pares.

Fueron siete novelas en la década de 50: (Una escena social (1853), Engaños y desengaños (1855), Los desposados (1855), El primer amor (1858), Juan de Aria (1858), La fascinación (1858) y Un drama en el campo (1859). El espíritu de estas primeras novelas se va a mantener a lo largo de toda la obra. Si bien leídas, Martín Rivas no es mucho mejor que algunas de estas producciones. Releerlas se torna necesario para poder armar el cuadro general.

\section{LOS PRIMEROS LECTORES}

Los lectores críticos de primera hora se dividieron, algunos escandalizados con el despliegue de muertes trágicas, de suicidios y de amores ilícitos, lo echaban a la basura; otros, sintieron falta de lo local, de la descripción del paisaje nacional, y hubo también aquellos que no hesitaron en prodigarle elogios. Lo cierto es que por lo que las fuentes de época indican, el éxito, especialmente femenino, fue inmediato.

Entre las repercusiones negativas, ya se ha señalado en más de una oportunidad la reseña en La Revista Católica, a poco de la publicación de su novela de estreno, donde se lo tachaba de fatalista, de impúdico por sus “inmundos conceptos", por la "corrupción”, etc. ${ }^{3}$. Cierto es que La Revista Católica, que había sido fundada en 1843 con el objetivo de recuperar terreno frente al avance de las ideas liberales provenientes de Europa, especialmente de Francia, representaba un extremo de la plataforma receptiva hacia los años cincuenta. Durante el gobierno de Manuel Montt (1851-1859), conservador pero laico, se había agudizado el conflicto entre la iglesia y las élites liberales (Stuven). Crecía un público de lectores y lectoras "pipiolos" que ya había aplaudido, en 1844, la Sociabilidad chilena de Francisco Bilbao, y repudiaba

\footnotetext{
Vargas Fontecilla, Francisco escribía: "Una escena social [...] novela original escrita por don Alberto Blest Gana, infestada del fatalismo, preñada de incidentes amorosos, de lances provocativos, de impúdicas pinturas muy a propósito para exaltar la fantasía y despertar en el corazón de la inexperta juventud la pasión más peligrosa y seductora que en él puede albergarse" (Cit. en Amunátegui Solar, 28-29).
} 
esos ataques a la producción literaria progresista ${ }^{4}$. Pero eso prueba también que Blest Gana, al ingresar a la carrera literaria, optaba conscientemente por adoptar una posición liberal desafiadora (compartida por su grupo) que antagonizaba abiertamente con el clero ultramontano. En la primera novela, por ejemplo, el protagonista se enamora perdidamente de una mujer casada y con un hijo: "Esto cortaba un tanto el vuelo de mi imaginación; ¿Cómo galantear a una mujer con un niño en las faldas, que puede responder a una mirada de amor mostrándonos el fruto de su amor legítimo? (Blest Gana, Una escena 54), y seguirá asumiendo su pasión incluso cuando descubra que no es ni siquiera casada, sino concubina.

En defensa de esa primera novela, encontramos la reseña del poeta Guillermo Matta, publicada también en El Museo y, más tarde, como prólogo de la primera edición en libro, en 1922. Para él había "pasado la época vergonzosa en que el soplo de los fanáticos encendía las hogueras", aprovechando para defenderse él mismo de los ataques que había recibido él también, tras la publicación de su poemario Cuentos en verso.

La crítica literaria local ejercía su papel controlador y modelador. La animadversión hacia el maestro francés se irradiaba desde la misma Francia, apenas llegaban a los puertos de Valparaíso libros como Les heures de travail, de Eugène Pelletan. La exposición descarnada de los vicios decurrentes del avance paulatino e inevitable de la voracidad depredadora del capitalismo. Como bien lo mostró años más tarde Lukács, Balzac se adelantó a su tiempo (Lukács 65-111). Pelletan lo expresa enfáticamente, después de releer con avidez y espanto sus obras completas, "il a trop sacrifié au reél, dans le sens du mal; c'est lá le défaut de sa qualité: le bien est reél aussi, sans cela le monde serait perdu" (Pelletan 106). Para los lectores más agudos de la Francia de su tiempo, la representación cruda del mundo anunciaba, como un peligro, el abismo de la modernidad y en ese sentido sus palabras resultan conmovedoras: "J'éprouve en ce moment une certaine tristesse". Hoy resulta difícil imaginar la conmoción que significó en su momento el ingreso de aspectos de la vida social que, por ser considerados sórdidos, inmorales y licenciosos, se habían mantenido marginados de la representación artística. Dicho de otra forma por Jacques Rancière, en alusión a los argumentos de época contra Flaubert:

4 En el capítulo consagrado a Carmen Arriagada, Susana Zanetti consigna una carta en la cual ésta "se indigna ante el ataque de la Revista Católica y la quema de ejemplares" (Zanetti 78). 
"A las puertas que mantenían la vida de las élites a distancia de la vida cotidiana las han seguido otras puertas [...]. Han confundido ellas mismas las relaciones entre el adentro y el afuera, lo noble y lo vulgar, al poner bajo la mirada del artista y del amante de la poesía el rostro oscuro de la sociedad" (Rancière 23). Todavía pocos años más tarde, en 1857, ocurriría el famoso proceso judicial por las escenas de adulterio de Mme. Bovary.

Más tarde, en 1859, tras la publicación conjunta de las cuatro novelas Engaños y desengaños, El primer amor, Juan de Aria y La fascinación ${ }^{5}$, Domingo y Justo Arteaga Alemparte escribirán, una reseña cada uno, en el periódico La Semana que ellos mismos editaban ${ }^{6}$. El primero elogiará la onda realista, "la ráfaga de concepción feliz" que se hacía llegar con El primer amor de Blest Gana, sin "estraños lances, ni peripecias inesperadas, ni acontecimientos extraordinários" para incorporar a "simples mortales como vosotros i yo, benévolos lectores, sin una pulgada mas de estatura que la ordinária (sic)" (Alemparte, D. 158-160). Pero su hermano, Justo, hacía de contrapeso y no esquivaba a la crítica que le merecía la misma novela, sobre la cual emitía objeciones que iban del tratamiento dado a los personajes a la incoherencia de sus actos, pasando por el lenguaje y el estilo demasiado demorado en las descripciones que, según él, pecaban por un exceso de balzaquismo: “...como Balzac, su maestro, se toma todo el tiempo que cree necesario, sin acordarse para nada del lector". Para él, "sin disputa", Juan de Aria era la mejor (Alemparte J. 210).

En Chile, los lectores de Blest Gana se pensaban distantes de los peligros de la metrópolis europea, al mismo tiempo seductora y perversa. Con la ayuda de la lectura de sus críticos, nuestro escritor en formación -se decían-sabría asimilar lo mejor del maestro, dejando de lado sus aspectos sombríos.

El realismo chileno nunca fue igual al francés, su modelo. Su modelo para imitar, pero también modelo del cual había que distanciarse. En el siglo XIX, la América postcolonial y católica miraba a París con fascinación y con recelo, y esa mirada ambigua se refleja en los modos de imitación y de repudio con que la enfrentaban los letrados latinoamericanos. En el caso de Blest Gana, esta actitud ambivalente la encontramos en sus páginas y también

5 Edición a la cual hacen referencia explícita estos dos articulistas y que no consta en la Bibliografía anotada de Román-Lagunas.

$6 \quad$ El semanario circuló entre 1859 y 1860 . Blest Gana publicó allí varias de sus crónicas y también su novela Un drama en el campo, de 1859. 
en la de sus lectores contemporáneos que aquí critican -como en el caso de la Revista Católica, recién citada- los excesos de realidad "degradada" y allí, le alaban la fidelidad en la pintura de las costumbres y de la vida en Chile.

En Los constituyentes de 1870, los mismos hermanos Arteaga Alemparte volverían a dedicarle unas páginas al escritor, por esa época ya consagrado. $\mathrm{Su}$ presencia en la nómina de diputados se justificaba, según ellos, no por sus cualidades parlamentares "poco memorables", pero sí por "su lugar en las letras chilenas", aunque no se ahorraban críticas a lo que consideraban un extremo realismo:

Los cuadros se trasladan a veces, de la realidad al libro sin pasar por el crisol del ideal. Esta falta de idealización artística, si los hace ganar en exactitud material, si los hace groseramente verdaderos, les quita aquella delicadeza, aquella amenidad, aquellas luces i fulgores con que la poesía transfigura la verdad en belleza. El arte supremo consiste, no en copiar la naturaleza con los sentidos, sino en copiarla con la fantasía, i el mejor artista no es el mas exacto, sino el mas patético (sic) (Alemparte, Constituyentes 622).

Conviene resaltar que hasta finales del siglo XIX la crítica no destacó a Martín Rivas del resto de la producción con la fuerza con que vendría a hacerlo después. Las lecturas de Diego Barros Arana y de Daniel Barros Grez serían consagratorias, de hecho, pero algo muy parecido había ocurrido con las repercusiones inmediatas de muchas de sus primeras novelas, desde Una escena social. Lo que se observa también es el hiato que se produce en las aproximaciones críticas entre mediados de 1860 y la década del noventa, lo cual se explica por el intervalo en la producción de Blest Gana y su alejamiento de la escena nacional.

En 1908 saldrá a la luz un ensayo de Pedro Nolasco Cruz, un novelista mediocre, antiliberal, defensor férreo de la iglesia católica y que ejercía su labor crítica como una "manifestación razonada, hecha con propósito docente", a modo de un censurador. Sus apreciaciones siguen esa doctrina y oscilan entre el elogio de determinados "aciertos" y lo que considera como lagunas o fallas. Observa un exceso de lo trágico en Blest Gana "cuando necesita desembarazarse de los personajes..." y le reprocha la abundancia de "palabras ociosas, de términos que se acercan a la idea y que necesitan agruparse para decir algo". Lo único que restituye del conjunto es su carácter nacional y su "vasta imaginación" (Nolasco 81-95). 
Para terminar este breve panorama crítico de la primera época, conviene referirse al estudio publicado por Domingo Amunátegui Solar en 1920, una primera visión de conjunto. Su lectura se regía por la consideración de la literatura como fuente documental para la historiografia y sus consideraciones sobre esta primera producción eran bastante restrictivas, aunque en su entender, desde Una escena social ya se revelaban "verdaderas dotes de novelista". Amunátegui retomaba la idea del realismo de Balzac focalizado en los aspectos más viles, feos y triviales de la humanidad y se apoyaba en las observaciones de George Pellisier autor de Le mouvement littéraire au siècle XIX, de 1889, para probar cómo el escritor chileno, al contrario, era capaz de mostrar facetas más solares. Pero Engaños y desengaños presentaba para él "un enlace inverosímil y artificioso", en El primer amor, el asunto le parecía vulgar e inverosímil, y Juan de Aria poseía "escaso mérito", sugiriendo parentescos de muchas de estas novelas con modelos europeos. En el caso de La fascinación y Los desposados, de temas y escenarios franceses, para él perdían su interés con el paso del tiempo debido a que habían sido superadas por los mismos autores franceses.

La cuestión es que desde Nolasco Cruz, pasando por Diego Barros Arana, Amunátegui Solar, Eliodoro Astorquiza, Silva Castro, Alone, Poblete Varas y Araya, todos ellos han sido unánimes en descartar prácticamente toda la producción anterior a La aritmética en el amor, premiada en 1860 como la primera novela chilena. La reciente publicación de un ensayo de Jaime Concha en el cual consigna brevemente el retrato que en El primer amor se hace de los cambios en las constumbres festivas de Santiago, es una excepción que es necesario aplaudir porque indica un cambio de perspectiva renovador hacia el conjunto de la obra (Concha, Costumbres 75-76).

\section{LA INTEMPERIE}

Aunque en esta producción, como en gran parte de sus libros posteriores, el tema amoroso se sitúa en el centro de la trama (Araya), ya es posible vislumbrar líneas de fuga que disparan en otras direcciones, apuntando hacia una aguda percepción del engranaje económico de la sociedad chilena de su tiempo. Digamos que en el Blest Gana de este periodo se combinan tintes de un romanticismo muy introyectado culturalmente desde las lecturas de la 
infancia y juventud ${ }^{7}$, con el realismo de su tiempo, al cual aspira el escritor liberal y progresista. En Una escena social, junto a la anécdota romántica central, ya vemos aparecer la observación distanciada de reuniones sociales donde se despliegan comportamientos cristalizados en función de las transacciones posibles. La omnipresencia del dinero como articulador de alianzas sociales y políticas es otro vértice importante que, como veremos, extiende sus tentáculos hacia toda la materia y las perspectivas narrativas. Así, descubrimos en esta primera novela un breve párrafo inicial en que el narrador protagonista ${ }^{8}$ se dirige hacia una residencia de la alta burguesía donde esa noche se ofrece un baile. Antes de ingresar a la casona, describe la brillante iluminación que se despliega desde los ventanales hacia la calle y en ese momento observa también a un grupo de mirones que, desde afuera, proyectan sus sombras de excluidos, sin poder acceder al festín. El sucinto comentario desarrollado a partir de esa constatación fugaz establece una línea directa con el novelista, con el cronista y con los demás narradores de muchas de sus próximas novelas:

Este rasgo característico de nuestra población santiaguina -concluye el narrador-podría servir de blanco a las curiosas investigaciones del escritor de costumbres, quien descubriría tal vez, en esos grupos tapados, amargos y desesperantes desconsuelos, mezclados con la crítica acre y punzante de los que miran, a la intemperie de la estación, la lujosa pompa y exterior alegría de los convidados (Blest Gana, Una escena 55).

En la segunda novela, Engaños y desengaños, el cinturón proletario de la capital chilena a mediados de siglo es descrito por otro narrador personaje como el "receptáculo de las inmundicias santiaguinas" y como una "población peor que salvaje" donde conviven "beodos, rateros y prostitutas" y "rostros de niñas del campo [...] puros e inteligentes en medio de la corrupción y estupidez”. Aquí, el narrador tutelar aconseja nuevamente: “...fecundo manancial de curiosos estudios, en el que algún venidero investigador hallará un abundante cuanto precioso depósito de tipos y costumbres no explotados

7 Rousseau, Byron, Goethe son constantemente citados en esa primera producción.

8 Son, en realidad, dos los narradores en esta novela, como comentaremos más adelante. El último párrafo del relato hace surgir, a modo de un Deus ex machina, al depositario de toda la aventura que él declara entonces haber transcrito. Blest Gana experimentaba alternativas compositivas... 
aún en nuestra joven existencia literaria" (Blest Gana, Engaños 111-112). La 'investigación' de la fauna social, de sus trizaduras y excrecencias, era una de las tareas del escritor que Blest Gana, inspirado en Balzac, defendería, años después en 1861, en su discurso en la Universidad de Chile.

Nuestro novelista siempre mantuvo esa mirada de reojo hacia la "intemperie" social que se introduce dentro de la escena burguesa con función disruptiva. Ya sea como un peligro o como una amenaza. En algunas de sus novelas más populares de la etapa siguiente (Martín Rivas, El loco Estero y Durante la Reconquista) serán fácilmente reconocibles los agentes del lado social obscuro por su fealdad, su ignominia o sencillamente por su falta de decoro9. Pero sería hacerle injusticia al novelista, el no consignar las ambigüedades y contradicciones con que sus narradores manejan este asunto, transformándolo en un problema no resuelto a ser compartido con el lector, un igual, un letrado como él. Vale registrar, entre otros, un breve pero detallado dibujo que hace de la gestualidad del huaso chileno en Un drama en el campo: "El huaso avanzó en las puntas de los pies, haciendo que el ruído de sus espuelas se apagara por medio de esa precaución, y tomando su sombrero con una mano, pasó con la otra la carta a la señora, mientras que con la que sostenía el sombrero llevaba hacía atrás un indómito cadejo de pelo, que cayó sobre su frente apenas le faltó el apoyo que lo sostenía" (Blest Gana, Un drama 6). La actitud sumisa que denotan todas sus actitudes (deslizarse de puntillas para no hacer ruido en casa de la señora Esteros, el ademán de sujetar firme el sombrero junto al cuerpo y tratar de sacarse el mechón de la frente) hablan de un modo de relación secular entre patrones y empleados. Este tipo de esquela le servirá más tarde, mucho más tarde, en la composición de los rotos y huasos en Durante la reconquista. Por otra parte, el escritor liberal profesaba, por esos años, la religión del progreso y de su poder civilizatorio que, con su fuerza transformadora y con el tiempo, actuaría "como una piedra arrojada a las aguas de un estanque", en beneficio de las clases menos favorecidas. Haciendo coro con sus pares letrados, para él la modernidad significaba la victoria de la civilización contra la barbarie, el progreso no generaba pobreza, sino que la erradicaba. Con los años, esta ideología irá sufriendo modificaciones y el

$9 \quad$ En Martín Rivas es impresionante la forma cómo el narrador se niega a describir con palabras la figura de una sirvienta en casa de la familia de medio pelo y apela para ello a un cuadro de Murillo (Blest Gana, Martín 64). 
escritor irá deslizándose hacia una perspectiva cada vez más desencantada de esa posibilidad y de la trayectoria del liberalismo.

\section{"LA EXTERIOR ALEGRÍA"}

La expresión remite directamente a un tema recurrente en toda su obra: el juego de apariencias como motor del engranaje social. La impronta balzaquiana había aterrizado en Santiago de mediados del siglo con toda su potencia y Blest Gana, sabemos, se propuso hacer despliegue de esa constatación, realizando el análisis del cuerpo social. La crónica "Un baile en Santiago", de 1953, puede leerse como soporte o corolario de esta postura. La tónica es la observación aguda y penetrante sobre los indicios superficiales de un entramado de sentimientos agazapados:

Estas reuniones en que se encuentran los diversos elementos de nuestra sociedad encierran mil verdades ocultas, mil curiosos incidentes que la mayor parte de los actores deja pasar sin hacer alto en ellos pero que ocupan seriamente la imaginación del fisiologista social [...] Cada poro del cuerpo social es un abismo donde se ocultan infinitos misterios (Blest Gana, El jefe 107).

Tanto el cronista como el novelista dan cuenta del peso que tenían, en la época, los bailes, los paseos en la Alameda y los escasos espectáculos en la dinámica de la vida social de la capital chilena. Importancia que tuvieron por lo demás en todos los centros culturales del diecinueve. En los salones burgueses se gestaban muchos de los grandes y los pequeños negocios, los matrimonios, las calumnias, las infamias, los entramados políticos. "Un baile es la arena de las terribles luchas del amor propio [...]. Allí se lanzan gemidos que nadie oye porque son el lamento desgarrador de un alma que se despedaza mientras el rostro sonríe..." (Blest Gana, El jefe 108), nos dice el cronista. El baile como exposición de mercaderías, como palco de la disimulación y de la hipocresía, donde mujeres de todas las edades se congregan para ver y ser vistas y para luchar por un lugar al sol en las lides sociales (Schwarz 172). Generalmente eran las damas de la alta burguesía quienes oferecían esas reuniones con el dinero de sus maridos -vivos o fallecidos-, de sus amantes o de alguna fortuna familiar heredada. Ese patrocinio de veladas mundanas significaba prestigio social, y ser parte de la selecta lista de convidados era un privilegio. El motivo será recurrente en toda la obra 
de Blest Gana desde su estreno. Pero lo será para confirmar la perversidad del método: en el salón se dan cita las muchachas en busca de pasiones y de matrimonios convenientes, los jóvenes irán atrás de amores avasalladores...y también convenientes, estarán allí también las matronas y casamenteras de miradas implacables, los solterones y solteronas, los ricos y los pobretones obnubilados, pero dificilmente la ecuación final se resolverá con encuentros armoniosos. La mayoría de las dieciocho novelas no termina en final feliz.

\section{"PARA ADQUIRIR ALGO ES NECESARIO TENER YA ADQUIRIDO"}

En esta primera fase veremos sucumbir en la selva espesa e impenetrable del tejido social burgués a cuatro de los protagonistas de las siete novelas: Alfredo de Una escena social, Luís D'Orville de Los desposados, Juan de Aria de la novela homónima y Fernando Reinoso de El primer amor. Todos ellos serán trágicamente derrotados por el sistema al cual intentan ingresar, apostando a la ilusoria alianza del amor con el dinero: "El interés y el amor -vaticina el experimentado amigo de Fernando Reinoso- son dos cosas diferentes, como el agua y el azúcar, jamás han podido mezclarse" (Blest Gana, El primer 168). A pesar de sus diferencias, los personajes se enfrentan con el mismo escollo de sus precarias situaciones financieras que determinan funestamente los destinos de sus relaciones amorosas. Una escena social maneja el final trágico de otra manera, pero al igual que en las demás, aquí el sistema sentimental que la rige se deja impregnar en la raíz por la misma temática del sexo a la venta que opera en muchas otras. En Los desposados, los jóvenes amantes son arrojados a una situación sin salida por el padre de la muchacha. La descripción pormenorizada del miserable cubículo al cual han sido reducidos ocupará una página entera, abundante en tintes patéticos ("lóbrego, húmedo y nauseabundo...") y prenuncia la tragedia final, anunciada al inicio con la escena de sus cadáveres en la Morgue del río Sena. Juan de Aria, el muchacho estudiante de derecho no tiene dinero suficiente para pagar las deudas adquiridas por el padre de su amada y verá su idilio brutalmente aniquilado por el otro pretendiente, inescrupuloso y asesino. En El primer amor, un poeta (el único literato en toda la producción blestganiana) pobre, enamorado de una mujer casada y riquísima, se irá degradando poco a poco hasta terminar desquiciado. Aquí también la pobreza ocupará al narrador, inspirado en la descripción balzaquiana de las habitaciones de Goriot: 
era un recinto triste y sombrío como todos los accesorios del mueblaje: la pobreza levantaba allí su descarnada faz viciándolo todo, hasta el aire que se respiraba, el que parecía frío y húmedo a pesar de la estación. Allí la miseria hacía oír su elocuente lenguaje, la historia de su desigual contienda con las necesidades de nuestras grandes poblaciones [...] Los muebles viejos y raídos, la alfombra cuyas flores se confundían con el color del fondo, la absoluta desnudez de las mesas sin lustre; todo allí hablaba del lujo de otros días y de comodidades desvanecidas (Blest Gana, El primer 24).

La visión de una sociedad de clases estancadas, sin posibilidad de ascensión económica, queda aquí estampada, aunque de manera más trágica que lo que se verá en las etapas siguientes, con una única excepción en Los trasplantados $(1904)^{10}$. Aquí la visión de la pobreza y de las dificultades materiales es cruda y detenida. Pero hay que advertir que no se trata de la indigencia o de la pobreza extrema de quienes nunca han tenido ningún acceso y son parte anónima de la chusma, del pueblo, sin individualización posible. Para ellos, vimos que el narrador blestganiano no tendrá lugar. Se trata aquí de la situación de quienes han bajado peldaños en la escala social ("veíase por todo, los vestijios (sic) de la antigua holganza..."), individuos que han tenido un pasado de bienestar económico o que al menos han tenido posibilidades de aspirar al ascenso y para los cuales, sin embargo, las puertas se van cerrando. En este sentido, el amigo de Martín Rivas, Rafael San Luis, es pariente de estos tres infelices.

Curiosamente, siendo el dinero el eje primordial, la obra del novelista chileno no se detendrá jamás en el detalle de las actividades laborales, las cuales serán ojeadas al pasar y con enorme grado de displicencia. En las novelas blestganianas alguien se ha hecho rico por las transacciones felices (no siempre muy lícitas) que ha realizado en algún momento del pasado, o ha heredado una fortuna familiar, o bien la ha obtenido a través de un matrimonio adecuado. Los jóvenes protagonistas de estas novelas de formación ${ }^{11}$ son pues, en su mayoría, estudiantes aspirantes a abogados cuyos destinos van a depender de la ayuda de alguien que los conecte con clientes poderosos. Hay también entre ellos un compositor (La fascinación) y el poeta de El

10 Aludo aquí al episodio de la familia Sagraves, sumergida en la pobreza más indigente, sin ninguna perspectiva de salvación, cuyo suicidio final en el Sena hace eco con el suicidio de los amantes de Los desposados.

11 Me refiero también al modelo del Wilhelm Meister de Goethe que las anima. Desarrollaré eso más adelante. 
primer amor, quienes, sin el consabido empujón, tampoco lograrán llegar a ningún lado.

Digamos que el centro de interés en Blest Gana es el mapeo de la sociabilidad burguesa y citadina, sus mecanismos de inclusión y de exclusión. El hecho de que dos de las siete primeras novelas (Los desposados y La fascinación) sean enteramente francesas y que otra (Juan de Aria) descarte explicitamente la localización, no es un detalle menor. Más tarde, hacia el final, vendrán Los trasplantados ${ }^{12}$ y Gladys Fairfield... Los componentes e ingredientes de lo que se ha convenido en llamar la identidad nacional, dependen de una máquina económica general cuya lógica es la misma que funciona en París, en Londres, en Madrid o en Santiago ${ }^{13}$. Por aquí pasa también su idea de progreso y de política contingente, ambos sometidos a intereses creados de las oligarquías rurales y de la burguesía citadina, condicionados ellos también al sistema global y, por eso mismo, merecedores de su creciente desconfianza con el pasar de los años.

Nada de esto puede haber sido planificado ni consciente, pero el conjunto de este material y la evidente y rica contradicción de todos los postulados blestganianos, leídos a la luz del presente, parecen dirigir sus ramas hacia la percepción premonitoria de un esquema global perverso en las entrañas del aparato nacional. Ese esquema se sitúa antes y en la raíz de cualquier posibilidad de construcción de un sentimiento patrio, clave a partir de la cual se lo ha leído siempre, incluso yo misma hasta no hace mucho. No tengo noticia de otro autor de su tiempo que haya publicado novelas "extranjeras" como él, a no ser Henry James. Si bien las diferencias entre James y nuestro narrador son enormes, sabemos la contundencia con que el escritor norteamericano/ británico incursionó en el análisis de los modos cómo el sistema internacional del capital rige en gran medida las relaciones en sociedad ${ }^{14}$.

El propósito de imitar las formas europeas para, a partir de ellas, construir una literatura auténticamente propia, como defiende Blest Gana en sus dos

12 Aquí se enfrenta el problema más de frente: ¿Cómo seguir siendo auténticamente nacionales en suelo extranjero?

13 El artículo "Identidad, costumbres y experiencia de la nación", de Jaime Concha, gira en torno a algo parecido. Aunque su desarrollo vaya en otra dirección, me ha servido aquí para reafirmar esta hipótesis (Concha 2018).

14 La última novela de Blest Gana, Gladys Fairfield, a mi modo de ver, posee una atmósfera jamesoniana. Es lo que defiendo en mi ensayo "Alberto Blest Gana: el mosaico final" (en prensa). 
textos programáticos ${ }^{15}$, era otra manera de enfrentarse al mismo dilema. Lo nacional estaría siempre a la sombra de los esquemas provenientes de la cultura heredada, venerada y odiada al mismo tiempo. Estos serán temas centrales para los intelectuales hispanoamericanos del fin de siglo y de todo el XX.

\section{EL TEMA FRANCÉS}

Sin entrar en el detalle del análisis, propongo al menos verificar lo que postulo, a través del examen general de esas novelas del primer periodo en las que sobresale "lo extranjero". La primera, Una escena social, ya trae en el título su vocación de tesis. Aunque su argumento se desarrolla en Santiago, contiene elementos que ya van en dirección de ese globalismo anticipado. De entrada, se presenta la relación del joven protagonista byroniano, Alfredo, con su mayordomo francés, Martín, a quien no se le concede ningún acceso directo a su lengua de origen. El narrador acota simplemente que "tenía su modo peculiar de expresarse, dando a sus frases el giro de su idioma" (52). Sabemos la importancia que irá cobrando con el tiempo la cuestión del afrancesamiento corruptor de la lengua, siendo sus ápices el siútico Agustín Encina de Martín Rivas y los rastacueros hispanoamericanos en París, protagonistas de Los trasplantados. Nada se dice sobre la trayectoria de ese cuarentón europeo que lo ha llevado a transformarse en un empleado particular en Chile, a no ser por una frase: “...era uno de esos hombres que, colocados por el destino en una esfera baja, presentan sin embargo un cierto interés, cuando los observamos de cerca..." (52). Con lo cual este personaje llegado del centro a la perferia se va a sumar a la galería de empobrecidos en toda la obra. Prueba de que los vaivenes del capitalismo no tienen apego a ningún lugar y que -esto lo aprendió Blest Gana no solo en Victor Hugo, en Balzac y en Stendhal, sino también a través de su vivencia de casi cuatro años como estudiante en la escuela militar de Versailles- los desastres económicos y las bancarrotas podían suceder en cualquier ciudad del mundo conectado de la posrevolución industrial. El influjo europeo en la sociabilidad chilena

15 "De los trabajos literarios en Chile" (1859) y "La literatura chilena: algunas consideraciones sobre ella" (1861). 
se deja ver desde la primera escena del libro, cuando el protagonista arroja al suelo un ejemplar de La nueva Eloísa de Rousseau, según él hastiado de tanta lágrima inutil y falsa. La vida de Alfredo se divide entre las lecturas, el fastidio (el mal del siglo) que lo aflige y la frecuentación de bailes y salones. Sus lecturas irán siendo citadas a lo largo de la historia: La Rochefoucauld, Hoffmann, Alexandre Dumas, Walter Scott, Goethe, Eugène Sue, Balzac. Algo de La dama de las camelias guarda este argumento que habla de la venta del sexo por dinero y de los derivados dilemas morales, arrepentimientos y consecuencias fatídicas. Los modelos comportamentales llegados de ultramar se combinaban con un escenario nuevo de arrayanes y de macetas de orégano, pero se mantenía la línea dorsal del esquema heredado.

Ya Los desposados se traslada completamente a París de la Primavera de los pueblos, en medio del desastroso levantamiento de junio de 1848 contra la Asamblea Nacional. La escena del heroico protagonista que se yergue sobre la barricada enarbolando una bandera, podría ser una descripción aproximada de la tela Barricada en la calle Soufflot, de Horace Vernet, y se vinculará de manera directa con otras escenas blestagnianas a lo largo de toda su obra: la de los jóvenes de la Sociedad de la Igualdad contra las fuerzas peluconas (Martín Rivas); la del motín liberal contra Portales (El ideal de un calavera) y la de la resistencia criolla contra la reconquista española (Durante la Reconquista). Blest Gana conservará mucho del mismo armazón narrativo romántico para describir estas escenas, exaltando patéticamente el coraje de los héroes liberales en oposición a las fuerzas conservadoras y retrógradas. El meollo de la narrativa de Los desposados irá a desplazarse del acontecimiento histórico para fijarse en sus funestas consecuencias que como comentamos antes, giran en torno al eje temático principal de la máquina económica, aquí protagonizado por una pareja de jóvenes franceses.

La tercera novela, La fascinación, también de ambientación completamente francesa, es un germen de motivos que veremos reaparecer con frecuencia, aterrizados en el espacio chileno de novelas "maduras". Aquí encontramos locuciones francesas debidamente traducidas y explicadas por el narrador a sus lectores, pero la intriga de pasiones triangulares en suelo parisiense nada tiene de específicamente europeo, a no ser por los escenarios de interiores y las descripciones de la ciudad (Latcham). Empezando por los ecos reconocibles en la trama central, resumible al esquema del joven veinteañero provinciano cuyo padre se empobreció antes de morir y que se enamora de una joven rica y citadina. Camilo de Ventours estudió leyes, como Martín Rivas, pero ha 
dejado atrás la profesión para dedicarse a su manía de compositor musical ${ }^{16}$. Su suerte es que la joven de sus desvelos -bella, viuda y rica-, se transformará también en su mecenas, dándole el puntapié inicial a su exitosa carrera. En la descripción de Adelaida de Farcy están empeñadas las mismísimas pinceladas utilizadas por lo general en la descripción de todas las bellas en Blest Gana. Los estereotipos de belleza llegaban a América con eventuales cambios de tonalidad, pero manteniéndose básicamente los mismos: la frescura de la tez, los cabellos abundantes y la frente diáfana, la redondez de los senos, la gracia del talle, los pies pequeños, las manos finas, etc... En este caso, como en el de Leonor Encina y de otras protagonistas, la belleza viene resaltada por el lujo que la enmarca. Pero además está aquí el detalle de la viudez de una mujer joven y rica, lo que merece comentario aparte.

La condición de viuda rica le ofrecía a la mujer en el siglo XIX una serie de privilegios: era libre y, al contrario de las solteras o casadas, adquiría derechos jurídicos plenos (Vergara Queiroz, xx), era dueña de su nariz a los ojos de los demás y, por lo tanto, altamente codiciada:

- ¿Casada?

- Viuda y rica.

- Un tesoro entonces.

- Que muchos ambicionan (La fascinación 80).

Son muchas las viudas jóvenes y ricas en la obra de Blest Gana. Las hay ambiciosas e inescrupulosas como Julia Valverde en La aritmética del amor y la española Violante de Alarcón en Durante la reconquista. Otras son un pozo de virtudes, como Laura en Engaños y desengaños, Luisa en El pago de las deudas y Adelaida de Farcy en La fascinación. Pero lo que las caracteriza a todas es su poder de seducción que deviene de la fuerza y la libertad que han obtenido del dinero heredado.

La fascinación presenta, por otro lado, un panorama bastante preciso de muchos de los espacios franceses de circulación de la alta burguesía y de la farándula, durante la primera mitad del siglo XIX. Ricardo Latcham, que la lee con bastante displicencia, pensando también en la prehistoria blestganiana, la considera mejor que las demás "novelículas parisienses" y siente que en ella la influencia de Balzac se hace notar con más peso (Latcham 507). La 
cuestión es que leer esta novela comparándola con La comedia humana no es la mejor manera de sacarle partido. Los dos escritores no son comparables. Blest Gana es treinta años menor, pertenece a otra generación, y tampoco era francés, lo que no es un detalle nimio. Fue un hispanoamericano que observó atentamente la Francia de los años 1847-1851, desde una perspectiva rastacuera, para usar un término de su diccionario. A partir de su experiencia juvenil en París y de las lecturas de otros escritores franceses, pudo percibir que muchas de las costumbres de los de su clase en Santiago, así como las dinámicas de la política chilena, se espejaban en la ciudad luz y así terminó por ir modulando su perspectiva periférica del centro capitalista y burgués. Hacia fines de 1858, cuando terminó la novela y la publicó, escribía al amigo José Antonio Donoso una carta en la que admitía un estado de ánimo oscilante que no le permitía concentrarse en la escritura como quisiera y sentía que aún no había escrito la obra "predilecta". Agregaba que en La fascinación había pintado algo de aquella existencia que tan bien conocía (Donoso 17).

Blest Gana observó, entre otras cosas, que en los espacios públicos los hombres ostentaban sus fortunas exhibiendo a sus mujeres, hijas o amantes, las cuales medían entre ellas sus fuerzas con los atuendos y carruajes con que circulaban. En esta novela, Blest Gana recoge mucho del material con que irá a desarrollar, cuarenta y seis años después, el fascinante episodio de las carreras de Longchamp, en Los transplantados. Así, describe que en los Campos Eliseos

[1]os suntuosos carruajes se deslizaban veloces por la calle central, conduciendo a bellas y soberbias mujeres o a efímeras reinas del proscenio que, en aquel lugar, como en todos los paseos públicos de París, luchan en riqueza y elegancia con las más altas y acaudaladas señoras, mientras que en la calle de la derecha los paseantes de a pie se movían en opuestas direcciones, entretenidos en pasar revista a las personas sentadas a lo largo del paseo (Blest Gana, La fascinación 121).

Las líneas fundamentales ya están aquí esbozadas: la forma como las mujeres compiten entre ellas, las diferencias de categoría (las reinas del proscenio, de un lado y las altas y acaudaladas señoras, de otro), diferencias que tienden a anularse en los paseos públicos. Además, están los contrastes entre el lujo de quienes desfilan sentados en sus carruajes y la plebe que camina ("de a pie") mirando y admirando a los ricos. Mucho de esa misma dinámica estará presente también en los numerosos paseos por la Alameda de Santiago de Chile durante las festividades patrias recogidas en varias de las novelas "maduras". 
En el caso de las descripciones de los protagonistas masculinos, el escritor repetirá básicamente un mismo esquema que también se inaugura aquí con el compositor francés de La fascinación. La relación entre la persona y el atuendo (aquí, de desajuste), los gestos ("la concentrada expresión de sus labios"), la mirada ("el fuego de sus ojos"), denotan la clase y las virtudes del joven veinteañero. A pesar de su éxito frente a las damas, sobre todo cuando toca sus composiciones en el violín, Camilo de Ventours "no es hermoso" - como no lo será tampoco Martín Rivas-y antes de abrir la puerta de entrada al mundo del éxito en los palcos parisienses, enamorándose y casándose con la rica Adelaida, se ve colocado frente a la alternativa de la pobreza comentada en más de una oportunidad. Lamentará su falta de fortuna y se quejará de las distancias que separan a ricos y pobres. La descripción de la casa de huéspedes donde vive en Saint Germain hace eco también con la de los tres empobrecidos mencionados en el aparte anterior. Allí, los dueños reúnen muebles viejos y en desuso ("restos de pasados esplendores") para acomodar a los jóvenes estudiantes pobres: "La pieza [...] era pobre y oscura. Las sombras de la tarde ocultaban un tanto la miseria del amueblado. Una cama de tijeras, un baúl, una mesa, dos sillas y un antiquisimo lavatorio, componían el mueblaje, sobre un piso de ladrillos pintados de rojo" (70). A lo largo de toda su producción, Blest Gana fue mostrando que la pobreza, así como la riqueza, se encontraban en todas partes.

Por fin, todavía en el campo francés, vale un comentario sobre la comparación que hace el narrador entre la gastronomía y la etiqueta francesas, y la pobre cocina chilena "que nos legaron los conquistadores". Evidentemente, sale victoriosa la francesa, pero los argumentos son en realidad muy reveladores del sentimiento anticolonial que persistía hacia 1858, en Chile. La influencia española sobre las costumbres criollas se percibe como indigesta, de cenas a puertas "cerradas herméticamente, carentes de algazara, de vino, de lujo y de licencia" (47). Esta perspectiva se iba a modificar con el tiempo y en novelas como El ideal de un calavera y, sobre todo en El loco Estero, las descripciones de la comida y de las fiestas populares chilenas fueron adquiriendo sabor y picardía propios.

\section{EL AMIGO}

Los jóvenes protagonistas, en su mayoría estudiantes con el propósito de hacerse un lugar al sol en la sociedad burguesa citadina, intentan cumplir los 
rituales de ingreso. La conexión de ese esquema con la novela de formación o Bildungsroman, en los términos con los cuales el mismo Wilhelm Meister la define en la novela de Goethe, es evidente: se trata de la trayectoria de un individuo quien, a partir de distintas experiencias vitales, aspira al desarrollo de sus potencialidades (artísticas, intelectuales, existenciales) y a una armónica y fecunda integración en la sociedad (Mazzari 72). En las narrativas de Blest Gana los protagonistas se presentan a camino de, y rumbo a esa integración, no siempre alcanzada. Algunos de ellos, sin una verdadera motivación de partida, víctimas del fastidio o de la falta de oportunidades materiales, vuelven a sentirse motivados por el impulso amoroso que se transforma para ellos en vía principal de acceso. Otros, a pesar de sus esfuerzos, ven colapsar las posibilidades en función de los agentes adversos que trabajan en su contra.

Al igual que en el modelo clásico, estos héroes en formación se irán relacionando con el mundo objetivo, a partir de los encuentros a lo largo del trayecto. Y aquí surge con frecuencia la figura del amigo, directamente conectada con el estatuto juvenil de estos protagonistas. En esta primera serie de novelas se destacan varios amigos con funciones narrativas que pueden ser diferentes: El amigo confidente del protagonista o testigo de la historia, e incluso eventualmente personaje activo. Además, Blest Gana que por esos años evidentemente experimentaba buscando una forma, también se valió de la amistad como mecanismo narrativo a través del cual los amigos son depositarios de la historia que narran. Eso es lo que ocurre en tres de estas narrativas ${ }^{17}$. En Una escena social, el amigo (sin nombre) aparece solo en los últimos párrafos, presentándose en un encuentro final que sirve como marco de toda la história anteriormente narrada por el protagonista, en primera persona. Ya en Engaños y desengaños, la dinámica narrativa está construida a través de un sistema de camadas de narradores unidos entre ellos por lazos de amistad. Un narrador inicial va a visitar a un amigo, Marcos, quien le cuenta la historia de otro amigo, Ismael, que a su vez será el narrador de su propia historia... Marcos se llamará también el amigo de Fernando Reinoso en El primer amor.

Son varios los nombres de personajes que se van a repetir en la producción blestganiana. De esta fase, Martín, el criado de Una escena social será

17 También las dos crónicas citadas de esta época ("Las manías" y "Un baile en Santiago") se apoyan en una estructura de amistad. El cronista y un amigo visitan la casa de una familia burguesa y van juntos después al baile y comentan entre ambos, sus impresiones. 
transformado en el célebre protagonista blestganiano de 1862, Adelaida de Farcy de La fascinación reaparecerá en Martín Rivas como Adelaida Molina, Manuela Esteros de Un drama en el campo surgirá como Manuela Estero en El loco Estero y Manuela se llamará también la hermana del protagonista de El primer amor. Difícil acertar con las motivaciones de esas retomadas onomásticas $^{18}$, pero lo que salta a primera vista al hacer el elenco es que invariablemente los personajes que comparten los mismos nombres son diametralmente opuestos entre sí. Eso valdría un examen más minucioso que no es el caso de realizar aquí.

Ya el parecido entre los amigos Marcos de El primer amor y Carlos de La fascinación me lleva a analizarlos brevemente en conjunto. En primer lugar, los caracteriza un significativo contraste de sus fortunas particulares con la situación de penuria de sus respectivos amigos y, además, comparten una misma admiración por las aptitudes artísticas de éstos. Lo primero que se muestra en ambas novelas, es esa relación de amistad. En El primer amor, una tarde del 24 de diciembre de 1850, Marcos está fumando cómodamente en su casa santiaguina, sentado en un sofá, minutos antes de que llegue el joven poeta Fernando Reinoso para ir juntos a la fiesta de Noche Buena en la plaza de Abastos. En La fascinación, la noche del 24 de abril de 1850 (el mismo día y el mismo año...), el compositor Camilo de Ventours y su amigo Marcos se encuentran sentados en un palco del teatro de la porte Saint-Martin de París, antes del comienzo del espectáculo. En esas escenas iniciales, ambos protagonistas confiesan a sus amigos que están perdidamente enamorados de mujeres que apenas han visto a lo lejos. Fernando ha cruzado una vez con Elena Malverde en el paseo de la Alameda y Camilo ha visto a la bailarina Julia Gualdini a distancia, desde el palco. Tanto Marcos como Carlos, hombres sensatos y, a pesar de jóvenes también, más experimentados y descreídos, practican un cinismo que les ha sido provechoso en materia sentimental. Ambos se transforman en confidentes y tutores, como va explicitado en $E l$ primer amor, y funcionan como puentes entre las subjetividades románticas e idealistas de sus amigos y la realidad factual y objetiva. Cada uno de los dos, a su manera, explicita las reglas del juego social. Pero lo que también conviene resaltar aquí es que, cuando necesario, salen en defensa de sus amigos artistas. En El primer amor, frente a la acusación de que los poetas 
pierden su tiempo y no son necesarios ("Tenemos necesidad de hombres en carreras más útiles"), Marcos va a responder: “...yo convengo en cuanto a la pérdida de tiempo, porque aquí las letras lejos de ser un beneficio ocasionan fuertes gastos $[\ldots]$....pero si los que ahora escriben pierden su tiempo, los que vengan más tarde encontrarán preparado el terreno y sus empeños serán menos estériles. En un país nuevo toda tarea de iniciación es ingrata y fastidiosa" (132) ${ }^{19}$. Ya el "ángel protector" del compositor francés, encantado al oírlo ("Diantre, exclamó al oír el final, ¿sabes que has compuesto una obra maestra?"), le va a presentar a un empresario que lo transformará en una "notabilidad musical". De ahí a que Camilo se desilusione de la bailarina y encauce su vida hacia el matrimonio con la viuda rica que le ha comprado sus primeras partituras, la novela gastará sus dilatadas páginas, algunas de las cuales extremadamente sabrosas.

En El primer amor, no solo el amigo como también el narrador observan la paulatina degradación del personaje ofuscado por la posibilidad de acceder al mundo material nada más que mediante el contacto con la "gente bien". La serie de encrucijadas que se va cerrando a medida que el personaje avanza empecinado en su pasión, compone cuadros de fuerza indiscutible. Aquí el ángel de la guardia se va cansando de la porfía de su pupilo: “Te romperás la frente, amigo, y tus ilusiones volarán como una bandada de golondrinas. Créeme, renuncia a ese amor. [...] Para consolarte y olvidar, entrégate a la poesía: haz versos a millares, no perdones ningún género de metro, persigue la rima..." (137). También le llamará la atención sobre el detalle de que Elena sea casada y se empeñará en introducirlo en otras tertulias para ayudarlo olvidar. Pero la fuerza centrípeta a la que Fernando se entrega lo volverá a atraer como un imán:

No hay remedio - dirá- yo he sido el loco al intentar oponerme a la pérdida de este niño. Que se amen; yo, entretanto, me lavo las manos [...] me había hecho la ilusión de formar de ti un discípulo. Eras dócil, y el amor te ha vuelto pertinaz y constante como una hormiga [...] veo que es necesario dejarte seguir tu destino. Has divisado a Santiago desde el cerro Santa Lucía, y te has dicho que todos los techos están a la misma altura [...] has mirado la vida desde la altura de tus ilusiones y amor propio, y te ríes del que te anuncia que arriesgas en 
tu marcha caer paras siempre. Bien está, acepto la partida, porque te quiero acompañar (Blest Gana, El primer 145-147).

No es poco relevante la alerta sobre los techos a la misma altura. Entre los aprendizajes necesarios está el comprender el funcionamiento de la malla social. Este Ícaro se rebela contra dos tabúes sociales a un mismo tiempo: el adulterio y la clase social de pertenencia. El desenlace trágico será su castigo, recordando que en la novela realista el deseo desorganizador del orden social se erradica de sus páginas mediante implacables "ceremonias de expulsión" (Bersani). Sin lugar a duda, estos amigos funcionan como portavoces del propio escritor, así como lo serán también sus narradores olímpicos de las fases siguientes y habría que verificar mejor las muchas semejanzas con el cronista.

Desde un principio, nuestro novelista ostentó un poder de imaginación y un sentido de la lengua que traducían el espíritu de su época con un estilo muy modelado por los autores románticos que lo habían formado. Su escritura en este periodo presenta un evidente influjo de esos modelos, dados a largas digresiones sin ningún sentido de síntesis, con flujo continuo de diversos asuntos y con prodigalidad de adjetivos. Hay poco desarrollo aún de la mirada más concreta sobre espacios, personajes y situaciones, aunque con excepciones. La perspectiva narrativa se apoya con más énfasis en un individualismo romántico volcado hacia dilemas espirituales y relaciones amorosas, por lo general trágicas o imposibles. El apoyo sistemático de sus tramas en periodos y episodios concretos de la historia nacional, tal cual se observará a partir de La aritmética en el amor, tampoco está presente.

Pero es necesario advertir que, si esas son algunas de las características más evidentes en estas primeras páginas revisadas sucintamente aquí, su obra se asoma por momentos a temas que serán fundamentales en la producción siguiente. En esta primera fase, ya paseaba la mirada de su ética liberal sobre la sociedad santiaguina, "tan pacífica, tan dormilona y apática", como afirmaba en su crónica de ese mismo año, criticándole la moral religiosa, la ignorancia y la hipocresía. Verificó también con detalle las formas perversas del aparato económico burgués. 


\section{BIBLIOGRAFÍA}

Amunátegui Solar, Domingo. "Bosquejo histórico de la literatura chilena". Revista de historia y geografia XXXIII. 37 (1920): 16-32.

Araya, Guillermo. "Historia y sociedad en la obra de Alberto Blest Gana". Historia de la Literatura Hispanoamericana, Tomo II. Org. Luis Íñigo Madrigal. Madrid: Cátedra, 1993. 163-191.

Arteaga Alemparte, Juan Domingo. "Ecos de la semana”. La Semana 10, 23 de julio de 1859.

Arteaga Alemparte, Justo. "Cuatro novelas de Alberto Blest Gana". La Semana 14, 20 de agosto de 1859 .

Arteaga Alemparte, Domingo y Justo. Los constituyentes de 1870. Santiago: Imprenta de la Libertad, 1870.

Bersani, Leo. "El realismo y el temor al deseo". Poétique 16 (1973): 176-195.

Blest Gana, Alberto. Una escena social (1853), en La fascinación, Una escena social, La aritmética en el amor. Santiago: Zig-Zag, s.f. Los desposados (1855), en La flor de la higuera. Santiago: Zig-Zag, 1956.

Engaños y desengaños (1855), en La flor de la higuera. Santiago: Zig-Zag, 1956. La fascinación (1858). Buenos Aires: Biblioteca "La Argentina", 1908. Juan de Aria (1858). Santiago: Guillermo E. Miranda, 1904. El primer amor (1858). París: Bouret e Hijo, 1884.

Un drama en el campo (1859), en Un drama en el campo, La venganza, Mariluán. París/México: Bouret e Hijo, 1876.

"De los trabajos literariodias en Chile". La semana 4 (1859): 51-52.

"La literatura chilena: algunas consideraciones sobre ella". Org. Klahn \& Corral, Los novelistas como críticos. México: FCE, 1991. 46-58.

El jefe de familia y otras páginas. Ed. Raúl Silva Castro. Santiago: Zig-Zag, 1956. Martín Rivas. Caracas: Ayacucho, 1977.

Epistolario de ABG I. Org. José Miguel Barros Franco. Santiago: DIBAM, 2011.

Cartas de mujeres en Chile 1630-1885. Org. Sergio Vergara Queiroz. Santiago: Andrés Bello, 1987.

Concha, Jaime. "Prólogo" a Martín Rivas. Caracas: Ayacucho, 1977.

"Identidad, costumbres y experiencia de la nación". Coord. Bernardo Subercaseaux, Historia crítica de la literatura chilena, Vol II. Santiago: Lom, 2018. 71-91.

Donoso, Ricardo. Un amigo de Blest Gana: José Antonio Donoso. Santiago: Imp. Universitaria, 1935.

Latcham, Ricardo. "Blest Gana y París". Org. Raúl Silva Castro, La literatura crítica de Chile. Santiago: Andrés Bello, 1969. 505-510.

Lukács, Georg, "Las ilusiones perdidas" y "La polémica entre Balzac y Stendhal”. Ensayos sobre el realismo. Buenos Aires: Siglo XXI, 1965. 
Matta, Guillermo. “Una escena social de Don Alberto Blest Gana”. El Museo 21 (1853): 326-328.

Mazzari, Marcus Vinicius. Romance de formação em perspectiva histórica. O Tambor de lata de G. Grass. São Paulo: Ateliê, 1999.

Nolasco Cruz, Pedro. "Don Alberto Blest Gana". La Unión 27 (28 de julio de 1908). Reprod. en Estudios sobre literatura chilena, vol. II. Santiago: Editorial Nascimento, 1940.

Pelletan, Eugène, Heures de travail, Tomo I. Paris: Ed. Pagnerre, 1854.

Ramos, Julio. Desencuentros de la modernidad en América Latina. Literatura y politica en el siglo XIX (1989). México: Tierra Firme, 2003.

Rancière, Jacques. Los bordes de la ficción. Buenos Aires: Edhasa, 2019.

Román-Lagunas, Jorge. "Bibliografía comentada de y sobre Alberto Blest Gana”. Iberoamericana 112-113 (1980): 605-647.

Schwarz, Roberto. "Dinheiro, memória, beleza (O pai Goriot)". A sereia e o desconfiado. Rio de Janeiro: Paz e Terra, 1981. 167-188.

Stuven, Ana María. "La iglesia católica chilena en el siglo XIX. Encuentros y desencuentros con la modernidad filosófica". Revista Teología y Vida 56 (2015): 187-212.

Vergara Quiroz, Sergio. Cartas de mujeres en Chile 1630-1885. Santiago: Andrés Bello, 1987.

Zanetti, Susana. "Carmen Arriagada: una lectora romántica". La dorada garra de la lectura. Buenos Aires: Beatriz Viterbo, 2002. 61-106. 